\title{
Issues and challenges faced by the indigenous students of Tripura in Primary-level to Higher Education: An overview
}

\section{Timothy Tripura ${ }^{1}$}

${ }^{1}$ Department of Linguistics \& Tribal Languages. Tripura University, Suryamaninagar799022, West Tripura, India.

Article History

Received:

03.09.2020

Revised:

25.11.2020

Accepted:

01.12 .2020

*Corresponding Author:

Timothy Tripura

Email:

timothymcveigh2@gmail.com

This is an open access article, licensed under: $\mathrm{CC}-\mathrm{BY}-\mathrm{SA}$

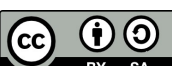

Abstract: The objective of the paper is to study the critical issues and challenges faced by the tribal students of Tripura in primary level to higher education from the perspective of their socio-economic status, medium of instructions in school, attitude of parents, teachers and peer groups etc. It will also give an analysis of the status of literacy rate, gross enrolment ratio and gender parity index. The present paper is mostly based on informal interviews (to few students, parents and teachers) and secondary data from various research studies including census data, committee reports on tribal, annual reports of tribal welfare ministry, Government organisations, Report on Selected Educational Statistics etc.

Keywords: Challenges, Issues in Higher Education, Socio-Economic, Tribal Students. 


\section{Introduction}

India is a home to a large variety of indigenous people. The Scheduled Tribe population represents one of the most economically impoverished and marginalized groups in India. With a population of more than 10.2 crores, India has the single largest tribal population in the world. This constitutes 8.6 per cent of the total population of the country [1].

The term 'Scheduled Tribes' first appeared in the Constitution of India. Article 366 (25) defined scheduled tribes as "such tribes or tribal communities or parts of or groups within such tribes or tribal communities as are deemed under Article 342 to be Scheduled Tribes for the purposes of this constitution". Article 342, which is reproduced below, prescribes procedure to be followed in the matter of specification of scheduled tribes.

\section{Article 342}

The President may, with respect to any State or Union territory, and where it is a state, after consultation with the Governor there of by public notification, specify the tribes or tribal communities or parts of or groups within tribes or tribal communities which shall, for the purposes of this constitution, is deemed to be scheduled tribes in relation to that state or Union Territory, as the case may be.

Parliament may by law include in or exclude from the list of Scheduled tribes specified in a notification issued under clause(1) any tribe or tribal community or part of or group within any tribe or tribal community, but save as aforesaid, a notification issued under the said clause shall not be varied by any subsequent notification.

Education forms an important component in the overall development of individuals, enabling them to greater awareness, better comprehension of their social, political and cultural environment and also facilitating in the improvement of their socio-economic conditions. These hold true in the case of the Scheduled Tribes in India.

Education is in fact, an input not only for economic development of tribes but also for inner strength of the tribal communities which helps them in meeting the new challenges of life [2] [3] [4]. It is the single most important means by which individuals and society can improve personal endowments, build capacity levels, overcome barriers, and expand opportunities for a sustained improvement in their well-being [5]. Despite the sincere and concerted efforts by the government for the overall development of the scheduled tribes, they are still far behind in almost all the standard parameters of development. They are not able to participate in the process of development, as they are not aware of most of the programmes and policies made for their upliftment [3] [6] [7]. This is mainly due to the high incidence of illiteracy and very low level of education among the tribal people. Hence, the educational status of the scheduled tribes and the role of governance in this direction are highly essential. It is well known that the educational background of tribes is very discouraging as compared to the rest of the population. So, education is an important avenue for upgrading the economic and social conditions of the Scheduled Tribes.

\section{Literature Review}

There exists a considerable literature on tribal development and growth of education among the tribals. According to Kumar [8] describe that despite special initiatives like Ashram schools, introducing vernacular at primary level, and teaching in local dialects, the tribals are still lagging behind the non-tribals. Under such circumstances, the government and policy makers should put best efforts to improve their educational status.

Rani [9] observed in her study that due to the language barrier the tribal children are unable to establish communication link with the teacher and thus leading to the termination of their education in some point or the other. Vaidyanathan \& Nair [10] suggested that teacher motivation contributes more to teaching - learning process than teacher competence. Jha \& Jhingran [11] have strongly advocated the use of the mother tongue or home language as medium of instruction in early stages of education. This assumes greater significance in the context of education of tribal children because their mother tongue is often quite distinct from the prominent languages in the state or regional languages and it is desirable to have a local teacher from the same tribal community. The Praitichi Committee Report [12] identifies cost of schooling, lack of motivation of teachers, lack of inspection, and the increasing dependence on private tutoring to be the main hurdles in the path of education for tribal children. 
Shah et al. [13] studied on Impact of Socio Economic Status (SES) of Family on the Academic Achievements of Students. This study examines two important aspects. Firstly, it studies the relationship between Socio-Economic Status (SES) of the family and academic achievements of their family members. Secondly, it investigates the impact of SES on the academic achievements of the Children. The analysis of the data shows that the socio economic status of a family positively effects the academic achievements of their children. It is also verified by the strong positive correlation between the two. The finding shows positive and strong correlation between SES and academic achievements of the children.

Gautam [14] in his article found that high "dropout" rates among tribal children He analysed that due to wrong medium of instruction, the appointment of non-tribal teachers in tribal areas and communication gap between the teachers and tribal children are the causes of high dropout rates in tribal schools.

Abdulraheem [15] explained that education as an important parameter for any inclusive growth in an economy and the policies have to focus on inclusive rather than divisive growth strategies.

\section{Methodology}

The present paper is mostly based on informal interviews (to few students, parents and teachers) and secondary data from various research studies including census data, committee reports on tribal, annual reports of tribal welfare ministry, Government organisations, Report on Selected Educational Statistics etc.

\section{Finding and Discussion}

\subsection{Educational status of Tribals in India and Tripura particularly}

All round development in 3 tier system of education (pre-school, School education in the primary/High/ Higher Secondary School level and Higher Education at College/University level) are interlinked and dependent on each other. Therefore it is important to look or study from the pre-school onwards to the college/University level in order to study the issues and challenges in higher education faced by the tribal students.

Higher education is regarded as a potential instrument of social change and national development. It is not only for creating enlightened and creative citizenry but also to make education a potential instrument of social change and national reconstruction. Being at the apex stage, higher education must cater to the needs and aspirations of the society and must gear to reach national goals through adequate expansion as well as quality improvement of education at all levels and in all respects.

\subsection{Gross Enrolment Ratio}

Estimated Gross Enrolment Ratio (GER) in Higher education in India is $25.2 \%$, which is calculated for 18-23 years of age group. For Scheduled Castes it is $21.1 \%$ and for Scheduled Tribes it is $15.4 \%$. GER for male population at all India level is $26 \%$ whereas for SC Males it is $21.8 \%$ and $16.7 \%$ for ST males. Similarly GER for female population at all India level $24.5 \%$ whereas for SC females are $20.2 \%$ and for ST females, it is $14.2 \%$ (AISHE 2016-17).

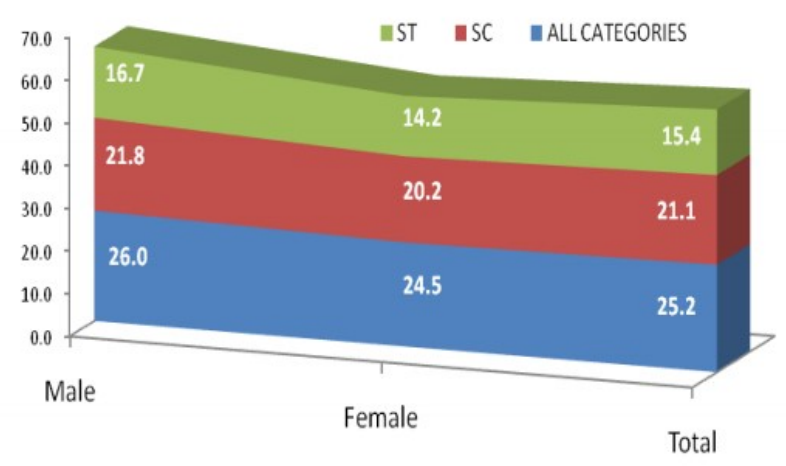

Figure 1. GER Distributed According To Social Category and Gender 
Figure 1 shows that the GER of the STs of India for Higher education (18-23 yrs of age group) in 2016-17 is lower than the SCs both in terms of males and females and over all percentage as well. Even in the primary (class I-V) and elementary (class I-VIII) level, the GER of the STs in India is declining as shown in the Table 1.

Table 1. Gross Enrolment Ratio (GER) for Scheduled Tribe Students in India

\begin{tabular}{|l|c|c|c|c|c|c|c|c|c|}
\hline \multirow{2}{*}{ Level/ Year } & \multicolumn{3}{|c|}{$\begin{array}{c}\text { Primary } \\
\text { (I-V) }\end{array}$} & \multicolumn{2}{c|}{$\begin{array}{c}\text { Upper Primary } \\
\text { (VI-VIII) } \\
\text { 6-10 Years }\end{array}$} & \multicolumn{3}{c|}{$\begin{array}{c}\text { Elementary } \\
\text { (I-VIII) } \\
\text { 6-13 Years }\end{array}$} \\
\cline { 2 - 10 } & Boys & Girls & Total & Boys & Girls & Total & Boys & Girls & Total \\
\hline $2013-14$ & 114.4 & 111.9 & 113.2 & 90.5 & 92.2 & 91.3 & 105.9 & 105.0 & 105.5 \\
\hline $2014-15$ & 110.6 & 108.2 & 109.4 & 93.0 & 95.2 & 94.1 & 104.4 & 103.7 & 104.0 \\
\hline $2015-16$ & 107.8 & 105.7 & 106.7 & 95.4 & 98.2 & 96.7 & 103.4 & 103.1 & 103.3 \\
\hline
\end{tabular}

Data source [16]:

For School Education: Unified-District Information System for Education (U-DISE), NUEPA

Although the GER of STs are lower than the SCs in Higher Education level and the GER is declining in Primary and Elementary level but when we look at the table-2 below, the GER of STs of India in Higher Education level is emerging from 11.3\% to 15.4\% in the year 2013-2017 which was a good sign.

Table 2. Gross Enrolment Ratio (GER) for Scheduled Tribe Students in India

\begin{tabular}{|c|c|c|c|c|c|c|c|c|c|}
\hline \multirow{2}{*}{$\begin{array}{c}\text { Level } \\
\text { Year }\end{array}$} & \multicolumn{3}{|c|}{$\begin{array}{c}\text { Secondary } \\
\text { (IX-X) 14-15years }\end{array}$} & \multicolumn{3}{c|}{$\begin{array}{c}\text { Senior Secondary } \\
\text { (XI-XII) 16-17years }\end{array}$} & \multicolumn{3}{c|}{$\begin{array}{c}\text { Higher Education } \\
\text { 18-23 years }\end{array}$} \\
\cline { 2 - 11 } & Boys & Girls & Total & Boys & Girls & Total & Male & Female & Total \\
\hline $2013-14$ & 70.3 & 70.1 & 70.2 & 36.7 & 34.1 & 35.4 & 12.5 & 10.2 & 11.3 \\
\hline $2014-15$ & 71.8 & 72.6 & 72.2 & 39.8 & 37.8 & 38.8 & 15.2 & 12.3 & 13.7 \\
\hline $2015-16$ & 73.7 & 75.4 & 74.5 & 43.8 & 42.4 & 43.1 & 15.6 & 12.9 & 14.2 \\
\hline $2016-17$ & NA & NA & NA & NA & NA & NA & 16.7 & 14.2 & 15.4 \\
\hline
\end{tabular}

Data source [17]:

For Higher Education: All India Survey on Higher Education (AISHE) reports, MHRD

Table-3. Gross Enrolment Ratio in Higher Education in Tripura (18-23 Years)

\begin{tabular}{|l|r|r|r|r|r|r|r|r|r|}
\hline \multirow{2}{*}{ State/UTs } & \multicolumn{3}{|c|}{ All } & \multicolumn{3}{c|}{ SC } & \multicolumn{3}{c|}{ ST } \\
\cline { 2 - 10 } & Both & Male & Female & Both & Male & Female & Both & Male & Female \\
\hline Tripura & & & & & & & & \\
\hline $2016-17$ & 19.1 & 21.5 & 16.8 & 17.9 & 20.5 & 15.3 & 13.7 & 15.2 & 12.3 \\
$2015-16$ & 16.9 & 19.9 & 14.0 & 14.6 & 18.0 & 11.3 & 10.9 & 12.9 & 9.1 \\
$2014-15$ & 16.8 & 20.2 & 13.5 & 15.5 & 19.8 & 11.2 & 10.5 & 13.9 & 7.6 \\
$2013-14$ & 15.4 & 17.9 & 12.9 & 1.4 & 1.6 & 1.1 & 0.9 & 1.1 & 0.7 \\
$2012-13$ & 14.1 & 16.6 & 11.7 & 12.1 & 14.4 & 9.7 & 8.1 & 10.2 & 6.3 \\
$2011-12$ & 12.4 & 14.6 & 10.2 & 10.6 & 12.6 & 8.5 & 6.4 & 8.3 & 4.8 \\
$2010-11$ & 13.6 & 16.0 & 11.0 & 10.1 & 11.7 & 8.4 & 6.3 & 7.9 & 4.9 \\
\hline
\end{tabular}

Data source [12]:

All India Survey on Higher Education (2016-17) reports, Govt. of India, MHRD. Dept. of Higher Education, New Delhi-2017 
GER of STs (18-23 YEARS) in higher education particularly in the state of Tripura is emerging from 6.3 to 13.7 in the year from 2010-11 to 2016-7 respectively as it is shown on Table 3. However when we look at the GER of female in India generally and Tripura particularly, boys outnumbered girls. This shows that females are not much given an opportunity as comparison to boys in pursuing higher education.

\subsection{Gender Parity Index}

The Gender Parity Index is a socioeconomic index usually designed to measure the relative access to education of males and females. This index is released by UNESCO. In its simplest form, it is calculated as the quotient of the number of females by the number of males enrolled in a given stage of education.

Gender Parity Index in primary, secondary and tertiary education is the ratio of the number of female students enrolled at primary, secondary and tertiary levels of education to the number of male students in each level. A GPI of 1 indicates parity between the sexes; a GPI that varies between 0 and 1 typically means a disparity in favour of males; whereas a GPI greater than 1 indicates a disparity in favour of females. Gender Parity Index (GPI) for STs is seen to be highest in the Secondary level (Classes IX-X) and lowest in Higher Education level as shown below in the Table 4.

Table 4. Gender Parity Index (GPI) for Scheduled Tribe Students of India

\begin{tabular}{|c|c|c|c|}
\hline $\begin{array}{c}\text { Level } \\
\text { Year }\end{array}$ & $\begin{array}{c}\text { Secondary } \\
\text { (IX-X) }\end{array}$ & $\begin{array}{c}\text { Senior Secondary } \\
\text { (XI-XII) }\end{array}$ & $\begin{array}{c}\text { Higher } \\
\text { Education }\end{array}$ \\
\hline $2013-14$ & 1.00 & 0.93 & 0.81 \\
\hline $2014-15$ & 1.01 & 0.95 & 0.81 \\
\hline $2015-16$ & 1.02 & 0.97 & 0.83 \\
\hline $2016-17$ & NA & NA & 0.85 \\
\hline
\end{tabular}
Data Source [10,11]:
Norhool Education: Unified-District Information System for Education (U-DISE),
For Higher Education: All India Survey on Higher Education (AISHE) reports, MHRD

\subsubsection{Trend in Gender Parity Index}

There is marginal increase in Gender Parity Index (GPI) for all the categories as shown in the figure 54. It has increased during the last 5 years, from 0.89 in 2012-13 to 0.94 in 2016-17. For SC, GPI has increased from 0.89 to 0.93 and for ST; it has increased from 0.79 to 0.85 during the period. GPI has also increased marginally across all the States. (AISHE 2016-17)

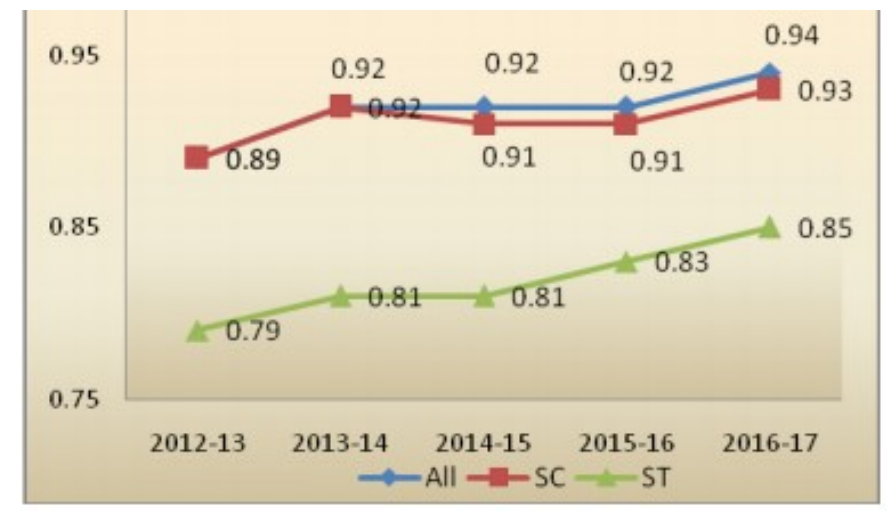

Figure-2. Category wise-GPI in Higher Education in India

Source [12]: All India Survey on Higher Education (2016-17) reports, Govt. of India, MHRD. Dept. of Higher Education, New Delhi-2017 
Although Figure 2 shows the increase GPI in India generally and both in STs and SCs respectively but when we look at the GPI ratio between STs and SCs of India STs are lacking behind SCs, because of this reason Government must take an immediate step so that the STs may also meet the level of other categories.

In Tripura, the Census-2011 data reveals that the overall ST literacy rate reached to 79.05 percent from earlier 56.50 percent in 2001. The ST literacy rate has significantly increased during intra-census period of 2001-2011 in the State, i.e; about 22.55percent, which is quite impressive.

Table-5. Gender Parity Index during Last 7 Years //

Gender Parity Index in Higher Education (18-23 Years)

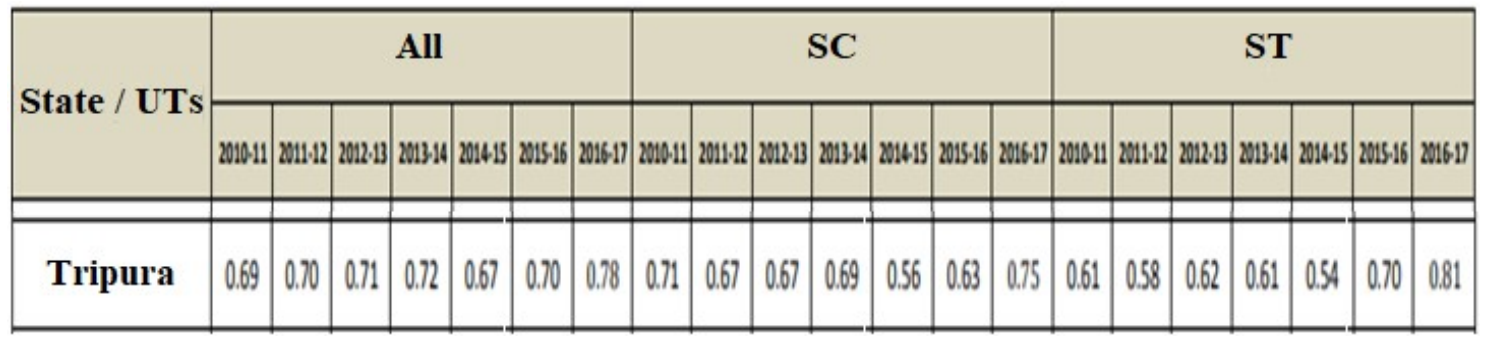

Source [12]: All India Survey on Higher Education (2016-17) reports,

Govt. of India, MHRD. Dept. of Higher Education, New Delhi-2017

On the Table 4, we can see that Gender Parity Index of STs in India is highest in the secondary level (IX-X). But as we move higher to Senior Secondary level and Higher Education level the GPI of STs in India is declining. However when we look at the GPI of STs particularly in Tripura, the GPI is increasing from 0.61 to 0.81 from 2010 -2016 respectively as shown on the table-5 above. This shows that number of females STs Enrolment in higher education is emerging.

\subsection{Steps Taken By the Government}

There are few steps taken by the government:

- MID-DAY Meal scheme

This scheme is introduced by the govt. of India with an objective to avoid classroom hunger, increase school enrolment, increase school enrolment, increase school attendance, address malnutrition, and improve socialisation among castes.

As per NEP 2020, the Mid-Day Meal Scheme will be extended to include breakfast. More focus will be given to students' health, particularly mental health, through the deployment of counsellors and social health.

- Beti bachao, Beti Padhao

It is a campaign of the Govt. Of India that aims to generate awareness and improve the efficiency of welfare services intended for girls in India and also to address the declining of Child Sex Ratio (CSR) and related issues of women empowerment over a life cycle continuum.

- In 2018-19, the Ministry of Human Resource Development launched the 'Samagra Shiksha' scheme which is a centrally Sponsored Scheme.

One of its objectives is to bridge social and gender gaps in school education.

$>$ To provide quality education to girls from disadvantaged groups, Kasturba Gandhi BalikaVidyalayas (KGBVs) have been sanctioned in Educationally Backward Blocks (EBBs) under Samagra Shiksha.

$>$ KGBVs are residential schools from class VI to XII for girls belonging to disadvantaged groups such as SC, ST, OBC, Minority and Below Poverty Line (BPL).

Lists of the state schemes provided to STs under Government of Tripura are:

$\checkmark$ Post-Matric Scholarship Scheme for ST students 
$\checkmark$ Pre-Matric Scholarship Scheme for ST students

$\checkmark$ Scheme of Development of PVTGs

$\checkmark$ State run stipend and scholarship to ST students.

Lists of the Central Sector schemes for the Education of Tribal Students:

$\checkmark$ Umbrella Scheme for Education of ST Students
i. Pre-Matric Scholarship
ii. Post-Matric Scholarship
iii. Vocational Training Centres
iv. Establishment of Hostels for ST boys and girls
v. Establishments of Ashram Schools

$\checkmark$ National Fellowship and Scholarship for Higher Education of ST Students

i. National Fellowship (PhD/MPhil)

ii. Top Class Scholarship

$\checkmark$ National Overseas Scholarship

Despite the fact that the Government initiative, literacy rate, and enrolment of the STs Students is developing in Tripura there are many issues and challenges that the STs students are facing in pursuing their education or higher education.

\subsection{Problems of Tribal Education in Tripura}

There are many critical Issues and challenges in the field of tribal education. They are:

1. Language barrier or medium of instruction especially in primary level which leads to bad effect at the higher education level.

2. Economic Condition- Majority of the students comes from a very poor family background.

3. Attitude of the parents-Parents often think that their children should find a remunerative work instead of going to school. And majority of the females are forced to marry when they reached $18-20$ years of age.

4. There is a lack of proper monitoring and evaluation between the Tribal welfare department and School Education Department.

5. Accommodations problem-there are no proper adequate classroom and toilets for boys and girls separately.

6. Lack of awareness about the academic courses in higher education and proper guidance.

7. Addicted to mobile and drugs (especially secondary to higher secondary level) which ultimately leads to the hindrances for pursuing higher education.

8. Lack of awareness about the various scholarship schemes.

9. Lack of Government English Medium School hence the students are compel to take admission in the Govt. Bengali Medium School which ultimately hinder them to adjust when they reach to the college and university level as the medium of instructions and answer writing in the exams at this level is English or Hindi.

\subsection{Suggestions}

Suggestions for improvement of tribal education are given below:

- Proper literacy awareness campaign should be organized to create the awareness about the importance of education especially to the illiterate parents and students should be encouraged.

- Mid-Day meal scheme should be properly and regularly maintained in the schools.

- Proper counselling and guidance must be given to the parents towards their attitude of education. Especially the parents must encourage their daughters to pursue for higher education instead of pressurising them for marriage.

- Parents and teacher meetings must be conducted at least twice in a month in every govt. schools.

- Medium of instructions in the class should be in their own mother tongue besides the state's language in the primary and pre-primary level.

- All study materials should be supplied in their mother tongue.

- More appointment of Local teachers and female teachers in the tribal areas.

- Residential schools - More residential schools should be established in each districts. 
- Stipends and various scholarships -more number of seats should be increased in National ST fellowship \& Scholarship for pursuing higher education, particularly in medical, engineering, and other vocational streams as well as for Humanities \& Social Science.

- Functioning of the schools must be checked frequently by the higher authority relating to the methods and system of teaching, working hours, and attendance registers.

- Drugs awareness campaign must be conducted in every village of the indigenous peoples.

- Govt. English medium schools should be established more in numbers.

\section{Conclusion}

Education is the key for the development of any individual human being. Same goes for the development of the indigenous people. Comparing to the other categories ( $\mathrm{SC}, \mathrm{OBC}$ etc) tribal has very low level of participation in education and higher education and drop-out ratio is also very high comparing to the other categories. There is no doubt that tribal students are developing in education however the pace of development is very slow in comparison to other categories.

There is also an existence of huge gender inequalities in Higher Education among Tribal Students. Majority of the students comes from a very poor economic background hence their money is insufficient for higher studies and were compel to marry at very early age, medium of instructions is also one kind of issue that the tribal children are facing, the seats are also very limited for the STs in higher education, there is also a problem of accommodation (no separate toilet for boys and girls especially in the government schools.

In National Educational Policy (NEP) 2020, GDP investment in Education to increase from $3 \%$ to $6 \%$ and Gross Enrolment ratio will be increased to $50 \%$ by 2035 .

NEP 2020 also raises the importance of mother tongue and regional language as a medium of instruction until class 5 , which is a good sign for the tribal students to study in their own mother tongue at the primary level.

NEP's 2020 proposal of a multi-disciplinary bachelor's degree in an undergraduate programme with multiple exit options is a good sign for the tribal students as it will not make them a drop- out students even if they wanted to leave the course or degree after a year as the new NEP 2020 policy implemented the new policies as follows:

* A certificate after completing 1 year of study

* A diploma after completing 2 years of study

* A Bachelor's degree after completion of a 3 year programme.

Under NEP 2020, there are also a concepts which has been given legislative permission to be formed such as-

$>$ Special education Zones, to focus on the education of underrepresented group in disadvantaged regions.

$>$ Gender Inclusion Fund, for assisting the nation in the education of female and transgender children.

All of the above mentioned points will eventually help the STs Students of India in general and Tripura particularly for more enrolment in education or higher education.

Although there are some of the state and central government scholarships for the STs Students however only 50 percent of STs in India are benefitted due to low in numbers of seats. More seats need to be increased for the Central Scheme scholarships. In order to bring the tribal students to the mainstream of economic development, there is an urgent need for government interventions and policy makers to address the issues and more funds should be allocated separately for the STs in the central and state budgets.

\section{References}

[1] C. Chandramouli, Census of India 2011: Scheduled Tribes in India, Ministry of Home Affairs. New Delhi, India, 2013.

[2] C. Ifeakor and A. I. Odo, "Analysis of the Marxist Theory on the Abolition of State: Its Implication to Nigeria Educational System", Journal of Humanities and Social Sciences, vol. 2, no. 2, pp. 62-68, Aug. 2020. 
[3] M. Mansor, W. A. Wan Adnan, and N. Abdullah, "A Step-by Step Process in Designing Personalized Reading Content for Slow Learner Children", International Journal of Humanities, Management and Social Science, vol. 2, no. 2, pp. 95 - 102, Dec. 2019.

[4] G. Roder, T. Ruljgaljig, C. -W. Lin, and P. Tarolli, "Natural hazards knowledge and risk perception of Wujie indigenous community in Taiwan," Natural Hazards, vol. 81, pp. 641-662, 2016.

[5] N. G. Bubu, "Management of Stress: From the Perspectives of the Natural Theory Philosophers", Journal of Humanities and Social Sciences, vol. 2, no. 2, pp. 69-74, Aug. 2020.

[6] N. D. Azeez and M. M. Lakulu, "Review the Success of the Mobile Government from the Government Perspective ", International Journal of Humanities, Management and Social Science, vol. 2, no. 2, pp. 103 - 109, Dec. 2019.

[7] J. M. R. Asio, "The Relationship between Academic Procrastination and Academic Performance of Freshmen Students from a Teacher Education Institution", Journal of Humanities and Social Sciences, vol. 2, no. 3, pp. 105-115, Dec. 2020.

[8] P. S. Kumar, "Problems of Tribal Education in India," Kurukshetra (ISSN 0021-5660), vol. 59, no. 7, pp. 26- 31, May 2011.

[9] M. Rani, "Tribal Languages and Tribal Education," Social Action, vol. 50, 2000.

[10] Vaidyanathan and Nair, "Elementary Education in Rural India: A Grassroots View," Strategies for Human Development in India, vol. 2, 2011.

[11] J. Jha and D. Jhingran, "Elementary Education for the Poorest and Other Deprived Groups, Centre for Policy Research," New Delhi, 2002.

[12] Anonymous. "All India Survey on Higher Education (2016-17) reports, Govt. of India, MHRD," Dept. of Higher Education, New Delhi-2017, 2017.

[13] M. Shah, A. Atta, M. I. Qureshi, and H. Shah, "Impact of Socioeconomic Status (SES) of Family on the Academic Achievements of Students," Gomal University Journal of Research, vol. 28, no. 1, pp. 12-17, 2012.

[14] V. Gautam, "Education of Tribal Children in India and the Issue of Medium of Instruction: A Janshala Experience," Conference on language development, language revitalization and multilingual education in minority communities in Asia, Bangkok, Thailand, SIL International, Mahidol University, UNESCO, 6-8 November 2003, 2003.

[15] A. Abdulraheem, "Education for the Economically and Socially Disadvantaged Groups in India," An Assessment Economic Affairs, vol. 56, no. 2, pp. 233-242, June 2011.

[16] Anonymous, Government of Tripura, State Literacy Mission Authority. Education (School) Department (literacy statistics): For School Education - Unified-District Information System for Education (U-DISE), NUEPA, 2016.

[17] Anonymous, Government of Tripura, State Literacy Mission Authority. Education (School) Department (literacy statistics): For Higher Education - All India Survey on Higher Education (AISHE) reports, MHRD, 2016. 